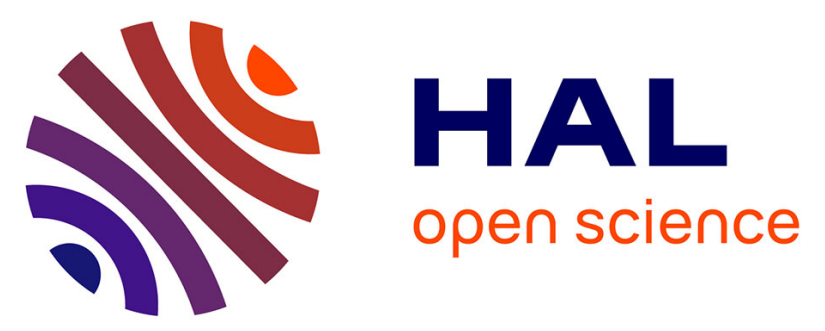

\title{
Formation of Brominated Disinfection Byproducts from Natural Organic Matter Isolates and Model Compounds in a Sulfate Radical-Based Oxidation Process
} Yuru Wang, Julien Le Roux, Tao Zhang, Jean-Philippe Croué

\section{- To cite this version:}

Yuru Wang, Julien Le Roux, Tao Zhang, Jean-Philippe Croué. Formation of Brominated Disinfection Byproducts from Natural Organic Matter Isolates and Model Compounds in a Sulfate Radical-Based Oxidation Process. Environmental Science and Technology, 2014, 48 (24), 10.1021/es503255j . hal01211472

HAL Id: hal-01211472

https://hal-enpc.archives-ouvertes.fr/hal-01211472

Submitted on 31 Oct 2016

HAL is a multi-disciplinary open access archive for the deposit and dissemination of scientific research documents, whether they are published or not. The documents may come from teaching and research institutions in France or abroad, or from public or private research centers.

$$
\text { Copyright }
$$

L'archive ouverte pluridisciplinaire HAL, est destinée au dépôt et à la diffusion de documents scientifiques de niveau recherche, publiés ou non, émanant des établissements d'enseignement et de recherche français ou étrangers, des laboratoires publics ou privés. 
1 Formation of brominated disinfection byproducts from natural

2

7

\section{organic matter isolates and model compounds in a sulfate} radical-based oxidation process

\author{
Submitted to
}

Environmental Science \& Technology

July, 2014

Yuru Wang, Julien Le Roux, Tao Zhang, and Jean-Philippe Croué*

Water Desalination and Reuse Center, King Abdullah University of Science and Technology, Thuwal 4700, Kingdom of Saudi Arabia

* Corresponding author: Tel.: + 966 (0) 28082984.

E-mail address: jp.croue@kaust.edu.sa 
19

20

21

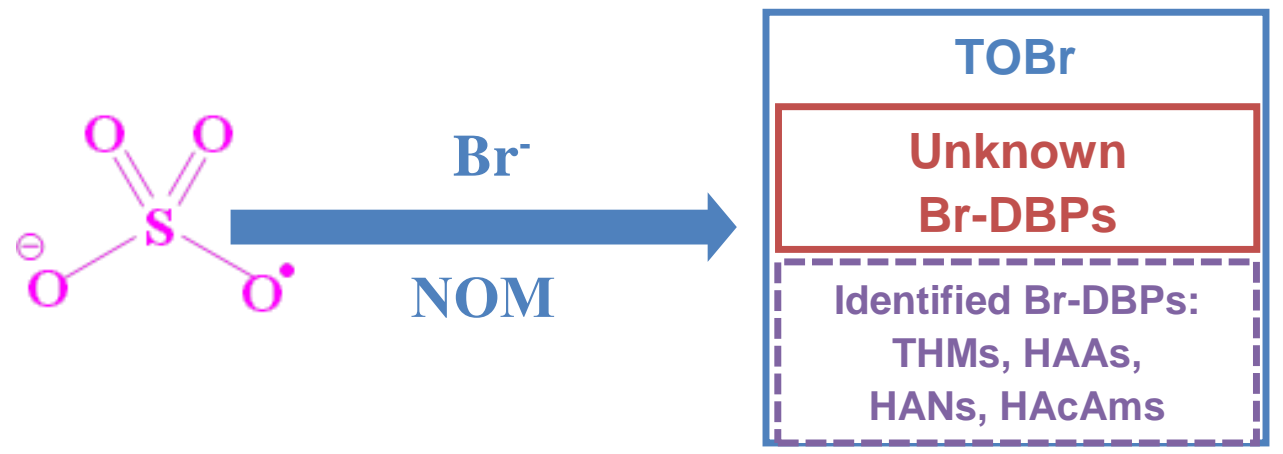

23

24

25

26

27

28

29

30

31

32

33

34

35

36

37

38

39 
41 Sulfate radical-based advanced oxidation process (SR-AOP) has received increasing application

42 interests for the removal of water/wastewater contaminants. However, limited knowledge is

43 available on its side effects. This study investigated the side effects in terms of the production of

44 total organic bromine (TOBr) and brominated disinfection byproducts (Br-DBPs) in the presence

45 of bromide ion and organic matter in water. Sulfate radical was generated by heterogeneous

46 catalytic activation of peroxymonosulfate. Isolated natural organic matter (NOM) fractions as

47 well as low molecular weight compounds were used as model organic matter. Considerable

48 amounts of TOBr were produced by SR-AOP, where bromoform (TBM) and dibromoacetic acid

49 (DBAA) were identified as dominant Br-DBPs. In general, SR-AOP favored the formation of

50 DBAA, which is quite distinct from bromination with $\mathrm{HOBr} / \mathrm{OBr}^{-}$(more $\mathrm{TBM}$ production). SR-

51 AOP experimental results indicate that bromine incorporation is distributed among both

52 hydrophobic and hydrophilic NOM fractions. Studies on model precursors reveal that low

53 molecular weight acids are reactive TBM precursors (citric acid $>$ succinic acid $>$ pyruvic acid $>$

54 maleic acid). High DBAA formation from citric acid, aspartic acid, and asparagine was observed;

55 meanwhile aspartic acid and asparagine were the major precursors of dibromoacetonitrile and 56 dibromoacetamide, respectively.

57

58

59

60

61

62 
64 Bromide ion is a ubiquitous component of natural waters and its concentration significantly

65 varies depending on the water source. ${ }^{1-3}$ When water is disinfected with chlorine, ozone or 66 chlorine dioxide, bromide ion can be quickly oxidized to hypobromous acid (HOBr), which

67 subsequently reacts with natural organic matter (NOM) to yield brominated disinfection

68 byproducts (Br-DBPs) in an analogous way to hypochlorous acid (HOCl). Elevated bromide

69 levels in source waters have been reported to induce a significant shift in speciation to Br-DBPs,

70 attributed to $\mathrm{HOBr}$ being a more efficient substitution agent in comparison with $\mathrm{HOCl}{ }^{4}$ It has

71 been shown that Br-DBPs are generally more cyto- and genotoxic than their chlorinated

72 analogues. ${ }^{5}$

73 In recent years, sulfate radical $\left(\mathrm{SO}_{4}{ }^{-}\right)$-based advanced oxidation processes (SR-AOPs) have 74 gained great scientific and technological interests for the decontamination of groundwater, 75 surface water and industrial wastewaters. Sulfate radical with a high standard reduction potential $76(2.5-3.1 \mathrm{~V})$ can react with a broad spectrum of organic contaminants at near diffusion77 controlled limits. ${ }^{6} \mathrm{SO}_{4}{ }^{\bullet-}$ can be generated through the activation of persulfates (i.e., 78 peroxymonosulfate (PMS) and peroxydisulfate (PDS)) by alkaline, UV, heat, or transition 79 metals. $^{7-10}$ Compared to hydrogen peroxide, persulfates in solid state are relatively stable, 80 therefore favoring storage and transportation. The strong oxidative capacity, relative stable 81 nature, and high aqueous solubility of its precursor compounds (i.e., PMS and PDS), in 82 combination with a variety of $\mathrm{SO}_{4}{ }^{\bullet-}$-generating techniques, make sulfate radical an excellent 83 alternative for eliminating recalcitrant organic pollutants. Recently, promising treatment 84 efficiency of SR-AOPs for waters with various challenging matrices (e.g., landfill leachate) has 
85 been reported. ${ }^{11-13}$ Moreover, there has been interest in the application of SR-AOPs as alternative 86 disinfectants. $^{14}$

87 Similarly to hydroxyl radical, the inorganic constituents of waters are usually competing scavengers of $\mathrm{SO}_{4}{ }^{\bullet-}$. Halide ions are known as important sink of $\mathrm{SO}_{4}{ }^{\bullet-}$. Particularly, bromide ion

89 is of special concern because its reactivity with $\mathrm{SO}_{4}{ }^{--}$is approximately 13 -fold higher than that of 90 chloride ion. ${ }^{15,16}$ In the presence of bromide ions, bromine atom $\left(\mathrm{Br}^{\bullet}\right)$ formation by $\mathrm{SO}_{4}{ }^{\bullet-}$ 91 oxidation is quite fast. Once $\mathrm{Br}^{\bullet}$ is formed, it quickly reacts with bromide ion to produce 92 dibromine anion radical $\left(\mathrm{Br}_{2}{ }^{\bullet-}\right) .{ }^{17}$ Besides, $\mathrm{Br}^{\bullet}$ and $\mathrm{Br}_{2}{ }^{\bullet-}$ can also undergo a series of reactions 93 with $\mathrm{Br}^{-}$and $\mathrm{H}_{2} \mathrm{O}$, leading to the generation of $\mathrm{BrOH}^{\bullet-}$ and $\mathrm{HOBr}^{-\mathrm{OBr}^{-}}$(see Table $\mathrm{S} 1$ of the 94 Supporting Information (SI)). ${ }^{17-21}$ Direct reaction of bromide ion with the monosubstituted 95 peroxide precursor of $\mathrm{SO}_{4}{ }^{\bullet-}$ (i.e., PMS) also occurs, however, the rate of active bromine 96 formation is extremely low when PMS is used alone without activation (Figure S1). ${ }^{22}$ In water, 97 these chain reactions involving reactive bromine species (i.e., $\mathrm{Br}^{\bullet}, \mathrm{Br}_{2}{ }^{\bullet-}, \mathrm{BrOH}^{\bullet-}$, and $98 \mathrm{HOBr} / \mathrm{OBr}^{-}$) can be terminated by reacting with $\mathrm{NOM}$ to form brominated byproducts, which 99 poses one of the primary issues of concern for the real water/wastewater application of SR100 AOPs.

101 To date, no information is available about bromine-incorporation into organic matter from 102 bromide-containing water during SR-AOPs. Therefore, the objectives of this research were to 103 investigate the formation and speciation of regulated and emerging DBPs with respect to NOM 104 properties, and to study and compare bromine-incorporation by SR-AOPs with bromination by $105 \mathrm{HOBr} / \mathrm{OBr}^{-}$. Brominated trihalomethanes (THMs), haloacetic acids (HAAs), and 106 haloacetonitriles (HANs) are the major Br-DBPs of concern in this study. Total organic bromine 107 (TOBr) was used to evaluate the total incorporation of bromine into organic molecules. 
Moreover, a range of structurally diverse model compounds including six amino acids (Group I), three phenolic compounds (Group II), and six carboxylic acids (Group III) which represent important moieties of NOM were tested to identify significant precursors of Br-DBPs and $\mathrm{TOBr}^{23}$ Amino acids featuring high levels of organic nitrogen may promote nitrogenous disinfection byproducts (N-DBPs) formation. Haloacetamides (HAcAms), an emerging class of $\mathrm{N}$-DBPs, were therefore monitored for experiments involving amino acids. The $\mathrm{CuFe}_{2} \mathrm{O}_{4}$ activated PMS process was employed to generate $\mathrm{SO}_{4}{ }^{--}$, rather than UV/PMS or UV/PDS, to avoid any interference from UV irradiation. ${ }^{24}$

\section{MATERIALS AND METHODS}

Materials. A detailed description of reagents and preparation procedures of $\mathrm{CuFe}_{2} \mathrm{O}_{4}$ spinel catalyst and bromine stock solution is provided in Text $\mathrm{S} 1$ (SI).

\section{NOM Samples and Selection of Model Compounds. Four previously isolated} NOM fractions were employed in this study (Table S2, SI). Three hydrophobic NOM fractions (i.e., hydrophobic acids or HPOA obtained from base desorption, hydrophobic or HPO isolated with acetonitrile/water desorption) showing very different chemical composition were selected: SR HPOA isolated from the Suwannee River (Georgia, USA); SPR HPOA isolated from the South Platte River (Colorado, USA) and CR HPO obtained from Colorado River (California/LA Verne, USA). The hydrophilic acid and neutral fraction (BR HPIA+N) isolated from Blavet River (Côte D'Armor, France) was also used in this work. NOM fractions were isolated using two slightly different comprehensive isolation protocols described elsewhere. ${ }^{25}$ Three groups of model compounds representing functional moieties of NOM were selected as NOM surrogates. Group I consisted of six amino acids (i.e., asparagine, glutamic acid, phenylalanine, tryptophan, tyrosine, and aspartic acid). Group II included three phenolic compounds (i.e., phenol, 
131 hydroquinone, and salicylic acid). Six carboxylic acids (i.e., citric acid, oxalic acid, malonic acid, 132 succinic acid, maleic acid, and pyruvic acid) were selected as group III to represent low 133 molecular weight acids. Structures and physicochemical properties of the model compounds are 134 presented in Table S3 (SI).

135 Experimental Procedure. Experiments were conducted in duplicate or triplicate at 136 room temperature $\left(20 \pm 2^{\circ} \mathrm{C}\right)$ in $250 \mathrm{~mL}$ capped amber bottles (individual bottle per contact time) 137 under headspace-free conditions. NOM isolate experiments were performed at a concentration of $138 \quad 5-7 \mathrm{mg} \mathrm{L}^{-1}$ (final DOC content of 2.2 to $2.7 \mathrm{mg} \mathrm{L}^{-1}$ was verified by TOC analyzer) in the 139 presence of $2 \mathrm{mg} \mathrm{L}^{-1}$ bromide $\left(25 \mu \mathrm{M} \mathrm{Br}^{-}\right)$buffered with $10 \mathrm{mM}$ tetraborate, unless otherwise 140 indicated. Reactions with model compounds were conducted with $50 \mu \mathrm{M}$ individual molecule 141 solutions in the presence of $4 \mathrm{mg} \mathrm{L}^{-1}$ bromide $\left(50 \mu \mathrm{M} \mathrm{Br}^{-}\right)$buffered with $10 \mathrm{mM}$ tetraborate. 142 Nitric acid and/or sodium hydroxide were used to adjust the initial $\mathrm{pH}$ of the solutions. For $\mathrm{SO}_{4}{ }^{\circ-}-$ 143 based tests, the reaction was initiated by adding an appropriate amount of $\mathrm{CuFe}_{2} \mathrm{O}_{4}$ spinel 144 catalyst and PMS (Sigma Aldrich, $\mathrm{KHSO}_{5} \cdot 0.5 \mathrm{KHSO}_{4} \cdot 0.5 \mathrm{~K}_{2} \mathrm{SO}_{4}$ ) stock solution. The $145 \mathrm{CuFe}_{2} \mathrm{O}_{4} / \mathrm{PMS}$ system generates $\mathrm{SO}_{4}{ }^{\circ-}$ as the major radical species and the sulfate radical yield 146 ratio from PMS was approximately 1 mol per mol. ${ }^{24}$ The bottles were immediately capped and 147 placed in a shaker $\left(\mathrm{IKA}^{\circledR} \mathrm{KS} 260\right)$ at a speed of $500 \mathrm{rpm}$ to maintain complete homogeneity 148 throughout the reaction. Samples were withdrawn at specific time intervals, immediately 149 quenched with excess sodium nitrite, and then filtered through $0.45 \mu \mathrm{m}$ glass fiber syringe filters 150 before analysis. Bromination was conducted as a comparison by dosing a predetermined amount 151 of $\mathrm{HOBr} / \mathrm{OBr}^{-}$into the same amount of NOM isolates and model compound solutions buffered 152 with $10 \mathrm{mM}$ tetraborate in $250 \mathrm{~mL}$ amber bottles without headspace. 
was measured by a Shimadzu TOC-Vcsh Analyzer. UV absorbance at $254 \mathrm{~nm}$ was recorded using a Shimadzu UV-2550 UV-VIS spectrophotometer. A liquid chromatography-organic

156 carbon detector (LC-OCD Model 8, DOC-LABOR, Germany) with a size exclusion 157 chromatography column was employed to compare NOM compositions. Three-dimensional 158 fluorescence excitation - emission matrices (FEEM) were obtained using an Aqualog® CDOM 159 Fluorometer (Horiba Scientific, Japan). Further details with respect to LC-OCD and FEEM 160 measurements are presented in Text S2 (SI).

161 Brominated organic compounds and residual oxidant. Samples for $\mathrm{TOBr}$ analysis were 162 enriched through adsorption on activated carbon column using a TOX sample preparatory unit 163 (TXA-03, Mitsubishi Chemical Analytech Co., Ltd, Japan). TOBr was then transformed into 164 hydrogen halide under high-temperature $\left(950^{\circ} \mathrm{C}\right)$ combustion of the activated carbon for at least 16530 min via an AOX-200 adsorbable halogen analyzer, and then collected in Milli-Q water as 166 bromide ion. Off-line quantification of bromide ion was performed by ion chromatography 167 (Dionex ICS-1600) equipped with a conductivity detector and a Dionex IonPac ${ }^{\circledR}$ AS-15 column $168(2 \times 250 \mathrm{~mm})$, using a $30 \mathrm{mM} \mathrm{KOH}$ solution at a flow rate of $0.4 \mathrm{~mL} \mathrm{~min}^{-1}$ as mobile phase. The 169 obtained $\mathrm{Br}^{-}$concentration was used to calculate the concentration of $\mathrm{TOBr}$ (as $\mu \mathrm{g} \mathrm{L}^{-1} \mathrm{Br}^{-}$). 170 During bromination experiments, residual bromine was monitored at the time of sampling by 171 DPD colorimetric method. Residual PMS was determined using colorimetric method after 172 reacting with $\mathrm{Co}^{2+}$ and $\mathrm{ABTS}$ to form a colored ABTS radical cation (further details in Text S3, 173 SI).

174 Br-DBPs analysis. Samples for the analysis of THMs/HAAs were extracted with methyl tert175 butyl ether (MTBE) within $1 \mathrm{~h}$ after quenching based on the EPA Method 551 and 552, 
176 respectively. HAcAms were extracted with ethyl acetate following a similar method to EPA

177 Method 551. THMs, HANs, and HAcAms were quantified on a gas chromatography (Agilent

178 7890A) equipped with an electron capture detector (GC-ECD), while MTBE extracts for HAAs

179 were analyzed on an Agilent 7890A GC equipped with Agilent 5975C inert XL MSD with Triple

180 Axis Detector (GC-MSD). DBPs were separated on a DB-1701 $(30 \mathrm{~m} \times 250 \mu \mathrm{m} \times 0.25 \mu \mathrm{m})$

181 capillary column. Analytical details are provided in the SI (Text S3).

182 RESULTS AND DISCUSSION

183 Characteristics of NOM Isolates. The NOM isolates exhibited a wide range of 184 SUVA $_{254}$ values (Table S2). SR HPOA showed the highest $\operatorname{SUVA}_{254}\left(4.97 \mathrm{~L} \mathrm{mg}^{-1} \mathrm{~m}^{-1}\right)$, 185 indicating a high degree of aromaticity, followed by SPR HPOA $\left(3.11 \mathrm{~L} \mathrm{mg}^{-1} \mathrm{~m}^{-1}\right)$ and CR HPO $186\left(2.08 \mathrm{~L} \mathrm{mg}^{-1} \mathrm{~m}^{-1}\right)$. BR HPIA+N showed the lowest $\mathrm{SUVA}_{254}\left(1.27 \mathrm{~L} \mathrm{mg}^{-1} \mathrm{~m}^{-1}\right)$, which is 187 characteristic of low content of aromatic moieties. Our previous works ${ }^{25}$ indicated that SR 188 HPOA is characterized by the predominance of fulvic acid structures derived from lignins and 189 tannins (high aromatic/phenolic carbon and carboxyl group contents) and CR HPO mainly 190 incorporates fulvic acid structures derived from terpenoids (lower aromatic carbon and phenolic 191 content, higher methyl group content) incorporating abundant polysaccharides moieties. SPR 192 HPOA showed an intermediate composition with both types of aromatic structures well 193 represented. ${ }^{25}$ In general, hydrophilic acids plus neutral NOM such as BR HPIA+N can be 194 described as a mixture of aliphatic hydroxy acids (e.g., low molecular weight acids), N195 acetylaminosugars, neutral carbohydrates, and neutral peptides. ${ }^{25}$ These differences in 196 composition between the four NOM fractions are in good agreement with the additional 197 structural information obtained by LC-OCD and FEEM analyses (Text S3 and Figures S2 to S4, 198 SI). 

HPOA were conducted to investigate the formation kinetics of $\mathrm{TOBr}$ and $\mathrm{Br}-\mathrm{DBPs}$ from bromide-containing water by SR-AOP. Recent studies have shown that $\mathrm{SO}_{4}{ }^{\bullet-}$ can lead to complete conversion of $\mathrm{Br}^{-}$to $\mathrm{BrO}_{3}{ }^{-}$in ultrapure water via $\mathrm{HOBr} / \mathrm{OBr}^{-}$as an intermediate path. ${ }^{2}$,

${ }^{26}$ However, no bromate formation was observed in this study in the presence of NOM. Moreover, 204 the $\mathrm{CuFe}_{2} \mathrm{O}_{4}$ catalyst had negligible impacts on the UV absorbance at $254 \mathrm{~nm}$ and TOC of NOM 205 isolates, suggesting insignificant adsorption of NOM on the catalyst (data not shown). Figure 1 206 illustrates TOBr and Br-DBPs evolution profiles by SR-AOP in the presence of $25 \mu \mathrm{M} \mathrm{Br}^{-}$at $\mathrm{pH}$ 207 7.5. TOBr was rapidly formed within the first $4 \mathrm{~h}$, where fast decomposition of PMS (> 70\%) 208 was observed. After 4 hours, TOBr concentration slowly decreased throughout the duration of 209 the experiment $(24 \mathrm{~h})$, which is probably due to reactions of sulfate radical with $\mathrm{TOBr}$ 210 components. Bromoform (TBM) formation showed a similar trend as $\mathrm{TOBr}$, suggesting that 211 TBM can be oxidized by the sulfate radicals remaining in the system, which was confirmed by 212 additional experiments (Figure S5). Yields of both dibromoacetic acid (DBAA) and 213 monobromoacetic acid (MBAA) gradually increased with reaction time. As opposed to TBM, 214 HAAs were not decomposed at longer reaction times. Low levels $\left(<4 \mu \mathrm{g} \mathrm{L}^{-1}\right)$ of 215 bromochloroacetonitrile (BCAN) and dibromochloromethane (DBCM) were produced due to the 216 presence of trace chloride in the potassium bromide salt used to prepare the solutions.

217 Figures 2-4 present the influence of PMS concentration, bromide ion concentration, and 218 solution $\mathrm{pH}$ on the formation and speciation of $\mathrm{TOBr}$ and $\mathrm{Br}-\mathrm{DBPs}$ by SR-AOP. In all cases 219 TBM and DBAA were the dominant identified Br-DBPs. TOBr and HAAs increased with 220 increasing PMS dosage, while the formation of TBM exhibited an increasing and then a 221 decreasing pattern because of its destruction with excess sulfate radicals. Increasing bromide 
222 concentration enhanced the formation of TOBr, TBM, and DBAA (Figure 3), which was 223 expected, as an increase in $\left[\mathrm{Br}^{-}\right]$led to a greater concentration of reactive bromine radical species 224 in the system. As shown in Figure 4, the formation of both TOBr and identified Br-DBPs was 225 highly $\mathrm{pH}$-dependent. TOBr and DBAA gradually increased with increasing $\mathrm{pH}$ until reaching a 226 maximum at $\mathrm{pH} 7.5$ and then rapidly decreased as $\mathrm{pH}$ was further increased to 9.5, which is 227 possibly related to the transformation of $\mathrm{SO}_{4}{ }^{--}$to hydroxyl radical through the reaction with $\mathrm{OH}^{-}$. 228 The high efficiency of $\mathrm{CuFe}_{2} \mathrm{O}_{4} / \mathrm{PMS}$ system at neutral $\mathrm{pH}$ was discussed in detail in a previous 229 study. ${ }^{24}$ The significant reduction of TOBr and DBAA at higher $\mathrm{pH}$ is also likely related to the 230 non-radical self-dissociation pathway of PMS in alkaline conditions. ${ }^{27}$ Besides, hydrolysis of 231 DBAA at $\mathrm{pH}>8.0$ is believed to be another reason responsible for its reduced concentration at 232 basic $\mathrm{pH}^{28}$ TBM formation increased with increasing $\mathrm{pH}$, which is consistent with the 233 commonly accepted explanation that base-catalyzed hydrolysis mechanisms play a significant 234 role in THM formation. ${ }^{29}$ This $\mathrm{pH}$ dependence of DBAA and TBM formation from NOM by SR235 AOP follows the behavior expected for chlorination/bromination of NOM, suggesting that 236 sulfate radical-induced formation of Br-DBPs showed some similarities compared to that of 237 chlorination/bromination. As a result, further studies were conducted to fully address the 238 differences and similarities between the two processes.

239 Figure 5 illustrates the formation and speciation of $\mathrm{TOBr}$ and Br-DBPs from various NOM 240 isolates by SR-AOP in the presence of $25 \mu \mathrm{M} \mathrm{Br}^{-}$at $\mathrm{pH} 7.5$ and for a contact time of $2 \mathrm{~h}$ in 241 comparison with bromination $\left(\mathrm{a} \mathrm{HOBr} / \mathrm{OBr}^{-}\right.$concentration of $\left.25 \mu \mathrm{M}\right)$. The comparison was 242 conducted to test if the bromination trend of these reactive bromine species generated in SR$243 \mathrm{AOP}$ is different from that of $\mathrm{HOBr} / \mathrm{OBr}^{-}$. Considerable formation of $\mathrm{TOBr}$ from $\mathrm{NOM}$ isolates 244 by sulfate radical oxidation of bromide-containing water was observed, ranging from $56-107 \mu \mathrm{g}$ 
$245 \mathrm{mg}^{-1} \mathrm{C}$ (Figure S6). On a molar basis, about $6.5-12.2 \%$ (Figure 5a) of the initial bromide was 246 transformed to TOBr. Nevertheless, SR-AOP produced much less TOBr than the bromination 247 process. Approximately 8.5 - 25\% of initial bromine was incorporated into TOBr, likely due to 248 (1) bromine being a preferable substituting agent ${ }^{4}$ and (2) possible subsequent decay of 249 brominated compounds by sulfate radical in SR-AOP system. ${ }^{2}$ It is known that identified DBPs 250 only account for a fraction of the total organic halogen (TOX). In fact, approximately $50 \%$ of the 251 TOX from chlorination of natural waters remains unknown, ${ }^{5,30-32}$ while over $70 \%$ formed by 252 chloramines has not been identified. ${ }^{32,} 33$ In the present study, quantified Br-DBPs only 253 constituted $22-33 \%$ of $\mathrm{TOBr}$ during SR-AOP, compared to $28-48 \%$ in bromination (Figure 254 5a). Speciation analysis revealed that DBAA was the predominant Br-DBPs during SR oxidation, 255 accounting for $90 \pm 6 \%$ of HAAs and $54 \pm 6 \%$ of total identified Br-DBPs by weight, followed 256 by TBM which contributed to $75 \pm 3 \%$ of the THMs and $31 \pm 3 \%$ of total identified Br-DBPs. In 257 contrast, NOM isolates were more susceptible to the formation of Br-THMs upon bromination. 258 TBM was by far the major contributor of total identified Br-DBPs (63 - 86\% on a weight basis) 259 upon bromination, while DBAA and TBAA contributed to $5.2-10.4 \%$ and $3.2-5.3 \%$, 260 respectively (Figure $5 \mathrm{~b}$ and $5 \mathrm{c}$ ). Besides, bromination tended to incorporate more bromine into 261 HAAs to form mainly DBAA and TBAA, while SR-AOP yielded mainly DBAA and MBAA (to 262 a lesser extent) with negligible TBAA formation, indicating again a different trend in Br-DBPs 263 formation from active bromine species formed in SR-AOP as compared with bromination.

264 For both SR-AOP and bromination, the formation of TOBr and Br-DBPs among different 265 types of NOM isolates exhibited distinct variation, which could be related to the different NOM 266 properties and their reactivities towards the oxidants. $\mathrm{TOBr}$ and $\mathrm{Br}-\mathrm{DBPs}$ formation correlated 267 well to the SUVA $_{254}$ values of the three hydrophobic NOM isolates during SR-AOP. 
268

269

270

271

272 273 fraction as well as hydrophobic acid with the highest $\mathrm{SUVA}_{254}$ value were the dominant sources

274

275

276

277

278

279

280

281

282

283

284

285

286

287

288

289

290

Interestingly the hydrophilic NOM isolate (i.e., BR HPIA+N) with the lowest $\mathrm{SUVA}_{254}$ formed high amounts of both TOBr and Br-DBPs similar to those formed from SR HPOA (Figure 5a).

These results demonstrate that SR-AOP favors the formation of DBAA in comparison to bromination which tends to produce more TBM. The DBAA yields from various NOM isolates during SR-AOP were 2.4 - 5.84 times higher than those from bromination. The hydrophilic of $\mathrm{TOBr}$ and Br-DBPs during SR-AOP, while good correlations $\left(\mathrm{R}^{2}>0.81\right)$ were observed between aromaticity of NOM and Br-DBP formation during bromination. The significant differences in distribution and speciation pattern of Br-DBPs upon SR-AOP and bromination suggest that sulfate radical-induced DBPs formation involves different reaction mechanisms as compared to bromination. In the SR-AOP system, both $\mathrm{SO}_{4}{ }^{\bullet-}$ and bromine radicals (e.g., $\mathrm{Br}{ }^{\bullet}$ and $\mathrm{Br}_{2}{ }^{\bullet-}$ ) can react with organic compounds via abstraction of hydrogen, addition to unsaturated compounds or one-electron oxidation. ${ }^{15}$ As such, multiple pathways could be involved in the formation of $\mathrm{TOBr}$ and $\mathrm{Br}-\mathrm{DBPs}$ by SR-AOP. To further understand the importance of precursor characteristics and the DBPs formation mechanisms in SR-AOP system, a broad spectrum of model compounds were tested as precursors.

\section{Formation of TOBr and Br-DBPs from Model Compounds. Table 1}

summarizes the incorporation of $50 \mu \mathrm{M}$ bromide ion (i.e., $4 \mathrm{mg} \mathrm{L}^{-1}$ ) into $50 \mu \mathrm{M}$ model compounds by SR-AOP (100 $\mu \mathrm{M}$ PMS and $\left.50 \mathrm{mg} \mathrm{L}^{-1} \mathrm{CuFe}_{2} \mathrm{O}_{4}\right)$ at $\mathrm{pH} 8$ and $24 \mathrm{~h}$ of contact time. Bromination of $50 \mu \mathrm{M}$ model compounds by $50 \mu \mathrm{M} \mathrm{HOBr}$ at $\mathrm{pH} 8$ was tested for comparison. Results for $2 \mathrm{~h}$ of reaction were also provided in Table S4 (SI). Consistent with the observation of bromine incorporation into NOM isolates, SR-AOP induced higher yields of DBAA and MBAA for nearly all the model precursors in comparison to bromination. 
291 Particularly, LMW acids (Group III) were certainly the most important precursors of TBM 292 during SR-AOP, while TBM yields from amino acids (Group I) and phenolic compounds (Group 293 II) were minimal. Upon SR-AOP and bromination, TBAA mainly originated from LWM acids 294 and phenolic compounds, respectively. For the SR-AOP system, TBM formation from each 295 aliphatic carboxylic acid predominated over the other identified Br-DBPs, whereas DBAA was 296 the major species from amino acids and phenolic compounds. Formation of N-DBPs was 297 observed by both SR-AOP and bromination of amino acids, although generally to a small extent 298 except for asparagine.

299 Among the studied model compounds, citric acid (a very HPI acid), was the most reactive Br300 DBPs precursor upon SR-AOP, yielding the highest amounts of TBM $\left(1144.3 \mu \mathrm{g} \mathrm{L}^{-1}\right)$, DBAA 301 (434.6 $\mu \mathrm{g} \mathrm{L}^{-1}$ ), and MBAA $\left(85.3 \mu \mathrm{g} \mathrm{L}^{-1}\right)$. More than $35.8 \%$ of initial bromide ion was 302 incorporated into $\mathrm{TOBr}$, where the identified Br-DBPs accounted for nearly 100\% of $\mathrm{TOBr}$. 303 Bromination of citric acid also yielded comparable TBM and to a lesser degree DBAA after $24 \mathrm{~h}$. 304 However, TBM formation from bromination was much slower as only 14.0\% was produced 305 within $2 \mathrm{~h}$, whereas more than $68.8 \%$ of the $24 \mathrm{~h}$ TBM yield was formed in $2 \mathrm{~h}$ by SR-AOP. 306 Sulfate radicals are known to efficiently react with most aliphatic carboxylic acids, leading to 307 oxidative decarboxylation of these compounds. ${ }^{34}$ Besides, reaction rate constants of $\mathrm{SO}_{4}{ }^{-{ }^{-}}$ 308 scavenging by carboxylate ions are siginificantly higher than their corresponding carboxylic 309 acids due to the fact that the former proceeds by one electron transfer from the carboxylate group to $\mathrm{SO}_{4}{ }^{- \text {- }}$ and the latter via hydrogen abstraction from $\mathrm{C}-\mathrm{H}$ bond. ${ }^{35}$ Consequently, decarboxylation

311 of aliphatic carboxylic acids by $\mathrm{SO}_{4}{ }^{--}$through one electron transfer is favored in this study as 312 most LMW acids were deprotonated into carboxylate anion at $\mathrm{pH} 8$ (see Table $\mathrm{S} 3$ for the $\mathrm{pK}_{\mathrm{a}}$ 313 values). For citric acid, $\mathrm{SO}_{4}{ }^{\bullet-}$ first abstracts one electron from the carboxylate group of $\beta$-carbon 
314 followed by the loss of $\mathrm{CO}_{2}$ and the formation of a corresponding $\mathrm{C}$-centered radical $315\left(\mathrm{HOC}^{\bullet}\left(\mathrm{CH}_{2} \mathrm{COO}^{-}\right)_{2}\right)$ which then converts the hydroxyl group of the $\beta$-carbon to a more stable 316 form of keto group. The resulting 3-oxopentanedioic acid ( $\left.\mathrm{HOOC}-\mathrm{CH}_{2}-\mathrm{C}(\mathrm{O})-\mathrm{CH}_{2}-\mathrm{COOH}\right)$, an 317 aliphatic $\beta$-keto acid, favors rapid halogenation at the two enolizable methylene groups doubly 318 activated by adjacent carbonyl groups. ${ }^{36}$ Subsequent decarboxylation/hydrolysis or oxidation of 319 the ketone gives rise to substantial TBM, DBAA, and MBAA formation. Bromination of 3320 oxopentanedioic acid at $\mathrm{pH} 8$ was reported to be relatively fast. ${ }^{37}$ As such, oxidative 321 decarboxylation of citric acid and subsequent transformation into 3-oxopentanedioic acid are 322 believed to be the rate-limiting step responsible for the slower TBM formation kinetics of citric 323 acid by bromination as compared to SR-AOP.

324 Pyruvic acid, an $\alpha$-keto acid, was another important TBM precursor by SR-AOP. TBM 325 accounted for $95 \%$ of the TOBr formed followed by a small amount of DBAA. Although to a 326 lesser extent, bromination of pyruvic acid also yielded considerable amount of TBM. 327 Chlorination of pyruvic acid was reported to proceed via dominated oxidation pathway (> $32898.5 \%$ ), yielding TCAA as major byproduct. ${ }^{38}$ In this study, the electrophilic substitution 329 pathway dominates given the prevailing TBM yields. The reaction pathway discrepancy between $330 \mathrm{SR}-\mathrm{AOP} /$ bromination and chlorination is likely due to a higher reactivity of bromine species than 331 chlorine in halogenating reactions. It is reasonable that $\alpha$-hydrogens in methyl group of pyruvic 332 acid undergo three successive halogenations upon the attack by bromine radicals or bromine to 333 give a tribromopyruvic acid $\left(\mathrm{CBr}_{3}-\mathrm{C}(\mathrm{O})-\mathrm{COOH}\right)$. Subsequent hydrolysis of this intermediate 334 releases TBM and oxalic acid. Based on the formation of DBAA by SR-AOP, decarboxylation 335 pathway that converts pyruvic acid to acetaldehyde $\left(\mathrm{CH}_{3} \mathrm{CHO}\right)$ should also occur. The resulting 336 acetaldehyde favors halogenation at $\alpha$-hydrogens, further oxidation leading to DBAA. 
$8.1 \%$ of initial bromide was incorporated into $\mathrm{TOBr}$ formed from maleic acid by SR-AOP, and TBM contributed to $43.6 \%$ of $\mathrm{TOBr}$. In contrast, bromination showed different patterns of speciation with $19.1 \%$ bromine being converted into TOBr, while TBM accounted for only $3.76 \%$ of TOBr. The significantly higher TBM formation by SR-AOP is believed to result from the

341 preference of sulfate radical on oxidizing unsaturated carbon bonds. ${ }^{39}$ Initially, the attack of

$342 \mathrm{SO}_{4}{ }^{--}$on the carbon-carbon double bond of maleic acid leads to the formation of oxobutanedioic 343 acid (HOOC-C(O)- $\left.\mathrm{CH}_{2}-\mathrm{COOH}\right)$ through hydroxylation along with isomerization. 344 Decarboxylation of oxobutanedioic acid occurs yielding pyruvic acid, which eventually leads to 345 the formation of TBM upon further reactions. It is also probable that oxobutanedioic acid, which 346 is also an aliphatic $\beta$-keto acid, contains an activated methylene group especially susceptible to 347 halogenation. After halogenation, decarboxylation likely occurs yielding a dibromopyruvic acid, 348 which can undergo halogenation followed by hydrolysis to yield TBM. Bromination of maleic 349 acid is known to proceed via anti-addition reaction on alkene group to form a stable mixture of 350 dibromomaleic acid enantiomers, ${ }^{40}$ which would explain the relatively higher $\mathrm{TOBr}$ and 351 considerably lower TBM formation observed.

352 For the three saturated dicarboxylic acids (i.e., oxalic acid, malonic acid, and succinic acid) 353 subjected to SR-AOP, both TBM and DBAA yields increased with increasing carbon chain 354 length. Insignificant substitution occurred on oxalic acid upon SR-AOP with less than $3.7 \%$ of 355 bromine incorporated into TOBr. Oxalic acid being the simplest dicarboxylic acid with its two 356 carbon atoms in the maximum oxidation state, decarboxylation proceeding twice to yield two 357 carbon dioxides should be the dominating reaction pathway, supported by the conclusion of 358 Zhang et al. ${ }^{24}$ Upon attack by sulfate radical, malonic acid also undergoes decarboxylation to 359 form acetic acid which can be hardly halogenated due to the inductive effect of carbonyl group 
and the absence of an electron donating alkyl group. In this study, succinic acid was the second most significant TBM precursor upon SR-AOP (see Table 1) with more than $14.4 \%$ of initial bromine being converted into TBM. It is likely that decarboxylation of succinate occurs twice followed by complete halogenation to yield two TBM. For bromination, both oxalic acid and succinic acid were characterized by a low bromine demand (see Table S5), and low TOBr and TBM formation, where only $2.3 \%$ and $1.5 \%$ of bromine was incorporated into $\mathrm{TOBr}$, respectively. Similar findings were also observed when oxalic acid was subjected to chlorination. $^{41}$ Bromination of malonic acid led to nearly no TBM formation, but yielded significant amount of DBAA with $9 \%$ of bromine being incorporated into DBAA after $24 \mathrm{~h}$ and more than $71 \%$ being formed within the first $2 \mathrm{~h}$. This high DBAA formation can be explained by the presence of an $\alpha$-carbon flanked by two adjacent carbonyl functional groups enhancing electrophilic substitution. Accordingly, malonic acid undergoes $\alpha$-bromination twice to give a dibromomalonic acid which subsequently decarboxylates to DBAA.

Upon SR-AOP, asparagine was a predominant precursor of dibromoacetamide (DBAcAm) (117.4 $\mu \mathrm{g} \mathrm{L}^{-1}$ at $\left.24 \mathrm{~h}\right)$ which along with DBAA $\left(74 \mu \mathrm{g} \mathrm{L}^{-1}\right.$ at $\left.24 \mathrm{~h}\right)$ were the major Br-DBPs generated. DBAcAm yield $\left(1068.6 \mu \mathrm{g} \mathrm{L}^{-1}\right)$ from bromination of asparagine was substantial with over $19 \%$ of initial bromine being incorporated into DBAcAm, which was more than 8 times of that from SR-AOP. DBAA and DBAN were also produced from bromination of asparagine (233.3 $\mu \mathrm{g} \mathrm{L}^{-1}$ and $112.9 \mu \mathrm{g} \mathrm{L}^{-1}$, respectively). DBAcAm was formed to a considerably higher extent by bromination. Besides, asparagine exhibited a very fast DBAcAm formation rate upon bromination with nearly $100 \%$ being formed within $2 \mathrm{~h}$, while DBAN slowly increased from $14.9 \mu \mathrm{g} \mathrm{L}^{-1}$ at $2 \mathrm{~h}$ to $112.9 \mu \mathrm{g} \mathrm{L}^{-1}$ at $24 \mathrm{~h}$. This result suggests that the majority of DBAcAm is not likely a result of the dihaloacetonitrile (i.e., DBAN in this study) hydrolysis pathway. ${ }^{42}$ In 
383 contrast, the side-chain amide group of asparagine plays a key role in DBAcAm formation, 384 similarly to the mechanism of asparagine chloramination proposed by Huang et al. ${ }^{43}$ Compared 385 to bromination, the lower DBAcAm formation from asparagine by SR-AOP may result from the 386 oxidation of the side-chain amide nitrogen group by sulfate radical and bromine radicals $(\mathrm{Br} \bullet / \mathrm{Br}$ $387(2.00 \mathrm{~V}))$ due to their high redox potential. Small amounts of bromoacetamide (BAcAm) were 388 generally detected from amino acids subjected to SR-AOP with asparagine as the major 389 precursor. However, this was not observed during bromination. Aspartic acid, selected as a 390 hydrophilic surrogate, was the second most reactive precursor of DBAA $\left(198.3 \mu \mathrm{g} \mathrm{L}^{-1}\right)$ and $391 \quad$ MBAA $\left(18.3 \mu \mathrm{g} \mathrm{L}^{-1}\right)$ and the principal contributor of DBAN $\left(29.2 \mu \mathrm{g} \mathrm{L}^{-1}\right)$ as a result of SR-AOP. 392 Similar formation patterns were also observed from chlorination of aspartic acid. ${ }^{41}$ The relatively 393 high formation of DBAA can be explained by the preferential formation of 3-oxopropanoic acid 394 at $\mathrm{pH} 8$ which is an aliphatic $\beta$-keto acid compound and a moiety known to have high 395 dihaloacetic acid formation potential. ${ }^{37,}{ }^{44}$ Bromination of amino acids exerted a significant 396 bromine demand, where nearly 100\% bromine was consumed within 2 h (Table S5). Asparagine 397 and tyrosine exhibited a high halogenation efficiency with $39.4 \%$ and $32.6 \%$ of initial bromine 398 being converted into $\mathrm{TOBr}$ in $24 \mathrm{~h}$, respectively, while the other amino acids were characterized 399 by lower TOBr formation $(<6 \%)$.

400 Model compounds with phenolic groups including tyrosine, phenol, and salicylic acid were 401 major precursors of TOBr upon both SR-AOP and bromination. This would be attributed to the 402 electron-donating effect of hydroxyl group attached to the aromatic ring, therefore facilitating the 403 electrophilic aromatic substitution by both reactive bromine radicals and bromine. For Group II 404 in the SR-AOP system, DBAA was the major identified Br-DBPs followed by TBM and MBAA, 405 while no formation of TBAA was observed (Table 1). On the other hand, bromination of model 
compounds with phenolic groups produced considerable amounts of TBM followed by small amounts of TBAA and DBAA.

Environmental Significance. It is proved in our previous study ${ }^{24}$ that PMS forms innersphere coordination (i.e., specific adsorption, a strong surface interaction which is not influenced by ionic strength) with the surface metal sites of $\mathrm{CuFe}_{2} \mathrm{O}_{4}$. In excess of PMS, one can expect that the bromine species generated in the solution would have limited access to the metal sites of the catalyst because these sites are already occupied by PMS. Figure 1a shows that bromine incorporation into the organic structure (i.e., bromination) finished within 4 hours, while the remaining PMS concentration in the solution was still above $10 \mu \mathrm{M}$. Therefore, PMS was in excess during the major bromination reaction. Although this study is based on the specific $\mathrm{CuFe}_{2} \mathrm{O}_{4}$-induced sulfate radical generation process, the result can still largely represent the bromination trend of organic matter in SR-AOPs. Our study reveals that $\mathrm{SO}_{4}{ }^{\bullet-}$ based-AOPs produces brominated byproducts including regulated and emerging Br-DBPs when applied to waters containing bromide ions. At bromide concentrations relevant to natural environment (i.e., $2.5-6.5 \mu \mathrm{M})$ our results showed that significant amount of $\operatorname{TOBr}\left(\right.$ i.e., $25-50 \mu \mathrm{g} \mathrm{mg}^{-1} \mathrm{C}$ ) with bromoform and dibromoacetic acid as the major identified Br-DBP species (i.e., 3.5 - 6 and 2 - 7

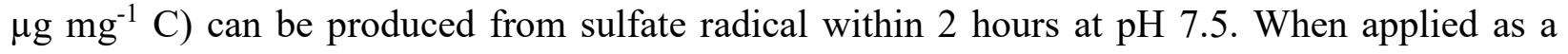
decontamination strategy for natural waters (i.e., bromide containing ground or surface waters with DOC content ranging from 2 to $10 \mathrm{mg} \mathrm{L}^{-1}$ ), the potential risk of producing substantial amount of regulated and non-regulated Br-DPBs from sulfate radical oxidation should be considered. In the case of potable water production, the formed Br-DPBs from sulfate radical reaction (i.e., can be viewed as a polishing treatment step) may contribute for a significant part to the DBP content obtained after final disinfection. Moreover, special attention should be given 
to those containing a substantial fraction of hydrophilic NOM species not easily removed by conventional water treatment process (e.g., coagulation). Groundwater is also usually characterized by a considerable content of hydrophilic organic matter. ${ }^{45}$ Particularly, SR-AOPs have already been applied in ground water remediation. ${ }^{46}$ Further investigation is required to elucidate the importance of other halide ions on the formation of halogenated byproducts by SRAOPs and to monitor the evolution of active halide species as well.

\section{ASSOCIATED CONTENT}

Supporting Information. Detailed descriptions of materials and methods as well as supporting tables and figures are included in the SI. This information is available free of charge via the Internet at http://pubs.acs.org.

\section{ACKNOWLEDGEMENTS}

Research reported in this work was supported by the King Abdullah University of Science and Technology (KAUST) and the Fundamental Research Funds for the Central Universities (GK201402031).

\section{REFERENCES}

1. Magazinovic, R. S.; Nicholson, B. C.; Mulcahy, D. E.; Davey, D. E., Bromide levels in natural waters: its relationship to levels of both chloride and total dissolved solids and the implications for water treatment. Chemosphere 2004, 57, (4), 329-335.

2. Fang, J. Y.; Shang, C., Bromate Formation from Bromide Oxidation by the UV/Persulfate Process. Environ. Sci. Technol. 2012, 46, (16), 8976-8983.

3. Richardson, S. D.; Fasano, F.; Ellington, J. J.; Crumley, F. G.; Buettner, K. M.; Evans, J. J.; Blount, B. C.; Silva, L. K.; Waite, T. J.; Luther, G. W.; McKague, A. B.; Miltner, R. J.; Wagner, E. D.; Plewa, M. J., Occurrence and Mammalian Cell Toxicity of lodinated Disinfection Byproducts in Drinking Water. Environ. Sci. Technol. 2008, 42, (22), 8330-8338.

4. Westerhoff, P.; Chao, P.; Mash, H., Reactivity of natural organic matter with aqueous chlorine and bromine. Water Res. 2004, 38, (6), 1502-1513. 
5. Richardson, S. D.; Plewa, M. J.; Wagner, E. D.; Schoeny, R.; DeMarini, D. M., Occurrence, genotoxicity, and carcinogenicity of regulated and emerging disinfection by-products in drinking water: A review and roadmap for research. Mutat Res-Rev Mutat.2007, 636, (1-3), 178-242.

6. P. Neta; V. Madhavan; Haya Zemel; Richard, W. F., Rate constants and mechanism of reaction of sulfate radical anion with aromatic compounds. J. Am. Chem. Soc. 1977, 99, 163-164.

7. Furman, O. S.; Teel, A. L.; Watts, R. J., Mechanism of Base Activation of Persulfate. Environ. Sci. Technol. 2010, 44, (16), 6423-6428.

8. Guan, Y. H.; Ma, J.; Li, X. C.; Fang, J. Y.; Chen, L. W., Influence of pH on the Formation of Sulfate and Hydroxyl Radicals in the UV/Peroxymonosulfate System. Environ. Sci. Technol. 2011, 45, (21), 93089314.

9. Johnson, R. L.; Tratnyek, P. G.; Johnson, R. O., Persulfate Persistence under Thermal Activation Conditions. Environ. Sci. Technol. 2008, 42, (24), 9350-9356.

10. Anipsitakis, G. P.; Dionysiou, D. D., Radical generation by the interaction of transition metals with common oxidants. Environ. Sci. Technol. 2004, 38, (13), 3705-3712.

11. Sun, J. H.; Li, X. Y.; Feng, J. L.; Tian, X. K., Oxone/Co ${ }^{2+}$ oxidation as an advanced oxidation process: Comparison with traditional Fenton oxidation for treatment of landfill leachate. Water Res. 2009, 43, (17), 4363-4369.

12. Deng, Y.; Ezyske, C. M., Sulfate radical-advanced oxidation process (SR-AOP) for simultaneous removal of refractory organic contaminants and ammonia in landfill leachate. Water Res. 2011, 45, (18), 6189-6194.

13. Zhen, G. Y.; Lu, X. Q.; Li, Y. Y.; Zhao, Y. C.; Wang, B. Y.; Song, Y.; Chai, X. L.; Niu, D. J.; Cao, X. Y., Novel insights into enhanced dewaterability of waste activated sludge by Fe(II)-activated persulfate oxidation. Bioresour. Technol. 2012, 119, 7-14.

14. Anipsitakis, G. P.; Tufano, T. P.; Dionysiou, D. D., Chemical and microbial decontamination of pool water using activated potassium peroxymonosulfate. Water Res. 2008, 42, (12), 2899-2910.

15. Neta, P.; Huie, R. E.; Ross, A. B., Rate constants for reactions of inorganic radicals in aqueoussolution. J. Phys. Chem. Ref. Data 1988, 17, (3), 1027-1284.

16. Yu, X. Y.; Bao, Z. C.; Barker, J. R., Free radical reactions involving $\mathrm{Cl}$-center dot, $\mathrm{Cl}$-2(-center dot), and SO4-center dot in the $248 \mathrm{~nm}$ photolysis of aqueous solutions containing $\mathrm{S}_{2} \mathrm{O}_{8}{ }^{2-}$ and $\mathrm{Cl}$. J. Phys. Chem. A. 2004, 108, (2), 295-308.

17. Zehavi, D.; Rabani, J., Oxidation of aqueous bromide ions by hydroxyl radicals. Pulse radiolytic investigation. J. Phys. Chem. 1972, 76, (3), 312-\&.

18. Neta, P.; Huie, R. E.; Ross, A. B., Rate constants for reactions of inorganic radicals in aqueous solution. J. Phys. Chem. Ref. Data 1988, 17, (3), 1027-1284.

19. Von Gunten, U.; Oliveras, Y., Advanced oxidation of bromide-containing waters: Bromate formation mechanisms. Environ. Sci. Technol. 1998, 32, (1), 63-70.

20. Avner Mamou; Rabanl, J.; Behar, D., Oxidation of aqueous bromide(1-) by hydroxyl radicals, studies by pulse radiolysis. J. Phys. Chem. 1977, 81, (15), 1447-1448.

21. Beckwith, R. C.; Wang, T. X.; Margerum, D. W., Equilibrium and kinetics of bromine hydrolysis. Inorg. Chem. 1996, 35, (4), 995-1000.

22. Fortnum, D. H.; Battaglia, C. J.; Cohen, S. R.; Edwards, J. O., The kinetics of oxidation of halide ions by monosubstituted peroxides. J. Am. Chem. Soc. 1960, 82, (4), 778-782.

23. Croué, J. P.; Korshin, G. V.; Benjamin, M. M., Characterization of natural organic matter in drinking water. AWWA Research Foundation: USA, 2000.

24. Zhang, T.; Zhu, H.; Croue, J.-P., Production of Sulfate Radical from Peroxymonosulfate Induced by a Magnetically Separable CuFe2O4 Spinel in Water: Efficiency, Stability, and Mechanism. Environ. Sci. Technol. 2013, 47, (6), 2784-2791. 
25. Hwang, C. J.; Krasner, S. W.; Sclimenti, M. J.; Amy, G. L.; Dickenson, E.; Bruchet, A.; Prompsy, C.; Gisele, F.; Croué, J. P.; Violleau, D.; Leenheer, J. Polar NOM : Characterization, DBPs, Treatment; the AWWA Research Foundation and American Water Works Association: USA, 2001.

26. Lutze, H. V.; Bakkour, R.; Kerlin, N.; von Sonntag, C.; Schmidt, T. C., Formation of bromate in sulfate radical based oxidation: Mechanistic aspects and suppression by dissolved organic matter. Water Res. 2014, 53, 370-377.

27. Rastogi, A.; Ai-Abed, S. R.; Dionysiou, D. D., Sulfate radical-based ferrous-peroxymonosulfate oxidative system for PCBs degradation in aqueous and sediment systems. Appl. Catal. B-Environ. 2009, 85, (3-4), 171-179.

28. Singer, P. C. In Basin Concepts of Disinfection By-Product Formation and Control, AWWA D/DBP Rule Teleconference, Presentation 1, 1993, pp 1-20.

29. Hua, G. H.; Reckhow, D. A., DBP formation during chlorination and chloramination: Effect of reaction time, pH, dosage, and temperature. J. Am. Water Work Assoc. 2008, 100, (8), 82-+.

30. Krasner, S. W.; Weinberg, H. S.; Richardson, S. D.; Pastor, S. J.; Chinn, R.; Sclimenti, M. J.; Onstad, G. D.; Thruston, A. D., Jr., Occurrence of a new generation of disinfection byproducts. Environ. Sci. Technol. 2006, 40, (23), 7175-7185.

31. Hua, G. H.; Reckhow, D. A.; Kim, J., Effect of bromide and iodide ions on the formation and speciation of disinfection byproducts during chlorination. Environ. Sci. Technol. 2006, 40, (9), 3050-3056. 32. Kristiana, I.; Gallard, H.; Joll, C.; Croue, J.-P., The formation of halogen-specific TOX from chlorination and chloramination of natural organic matter isolates. Water Res. 2009, 43, (17), 4177-4186. 33. Diehl, A. C.; Speitel, G. E.; Symons, J. M.; Krasner, S. W.; Hwang, C. J.; Barrett, S. E., DBP formation during chloramination. J. Am. Water Works Assoc. 2000, 92, (6), 76-90.

34. Madhavan, V.; Levanon, H.; Neta, P., Decarboxylation by $\mathrm{SO}_{4}{ }^{\circ-}$ radicals. Radiat. Res. 1978, 76, 12-22.

35. Grgic, I.; Podkrajsek, B.; Barzaghi, P.; Herrmann, H., Scavenging of $\mathrm{SO}_{4}^{-}$radical anions by monoand dicarboxylic acids in the $\mathrm{Mn}(\mathrm{II})$-catalyzed S(IV) oxidation in aqueous solution. Atmos. Environ. 2007, 41, (39), 9187-9194.

36. Larson, R. A.; Rockwell, A. L., Citric acid: Potential precursor of chloroform in water chlorination. Naturwissenschaften 1978, 65, (9), 490-490.

37. Dickenson, E. R. V.; Summers, R. S.; Croue, J.-P.; Gallard, H., Haloacetic acid and trihalomethane formation from the chlorination and bromination of aliphatic beta-dicarbonyl acid model compounds. Environ. Sci. Technol. 2008, 42, (9), 3226-3233.

38. Reckhow, D. A.; Singer, P. C., Mechanisms of organic halide formation during fulvic acid chlorination and implications with respect to preozonation. Lewis publishers, Inc.: Chelsea, Michigan, 1985; Vol. 5.

39. Antoniou, M. G.; de la Cruz, A. A.; Dionysiou, D. D., Intermediates and Reaction Pathways from the Degradation of Microcystin-LR with Sulfate Radicals. Environ. Sci. Technol. 2010, 44, (19), 7238-7244. 40. Weiss, H., Aqueous bromination of maleate and fumarate ions. J. Am. Chem. Soc. 1977, 99, (5), 1670-1672.

41. Bond, T.; Henriet, O.; Goslan, E. H.; Parsons, S. A.; Jefferson, B., Disinfection Byproduct Formation and Fractionation Behavior of Natural Organic Matter Surrogates. Environ. Sci. Technol. 2009, 43, (15), 5982-5989.

42. Shah, A. D.; Mitch, W. A., Halonitroalkanes, Halonitriles, Haloamides, and N-Nitrosamines: A Critical Review of Nitrogenous Disinfection Byproduct Formation Pathways. Environ. Sci. Technol. 2012, 46, (1), 119-131.

43. Huang, H.; Wu, Q. Y.; Hu, H. Y.; Mitch, W. A., Dichloroacetonitrile and Dichloroacetamide Can Form Independently during Chlorination and Chloramination of Drinking Waters, Model Organic Matters, and Wastewater Effluents. Environ. Sci. Technol. 2012, 46, (19), 10624-10631. 
$550 \quad 44 . \quad$ Hureiki, L.; Croue, J. P.; Legube, B., Chlorination studies of free and combined amino acids.

551 Water Res. 1994, 28, (12), 2521-2531.

552 45. Gallard, H.; Allard, S.; Nicolau, R.; von Gunten, U.; Croue, J. P., Formation of lodinated Organic 553 Compounds by Oxidation of lodide-Containing Waters with Manganese Dioxide. Environ. Sci. Technol. $554 \quad 2009,43,(18), 7003-7009$.

555 46. Sra, K. S.; Thomson, N. R.; Barker, J. F., Persulfate injection into a gasoline source zone. J. 556 Contam. Hydrol. 2013, 150, 35-44. 
Table 1. Formation of TOBr and Br-DBPs from Model Compounds

\begin{tabular}{|c|c|c|c|c|c|c|c|c|c|c|c|c|c|c|c|c|}
\hline \multirow[t]{2}{*}{ Compound } & \multicolumn{2}{|c|}{$\operatorname{TOBr}\left(\mu \mathrm{g} \mathrm{L}^{-1}\right)$} & \multicolumn{2}{|c|}{ DBAA $\left(\mu g \mathrm{~L}^{-1}\right)$} & \multicolumn{2}{|c|}{$\operatorname{MBAA}\left(\mu g \mathrm{~L}^{-1}\right)$} & \multicolumn{2}{|c|}{ TBAA $\left(\mu \mathrm{g} \mathrm{L}^{-1}\right)$} & \multicolumn{2}{|c|}{ TBM $\left(\mu \mathrm{g} \mathrm{L}^{-1}\right)$} & \multicolumn{2}{|c|}{ DBAN $\left(\mu \mathrm{g} \mathrm{L}^{-1}\right)$} & \multicolumn{2}{|c|}{ DBAcAm $\left(\mu g \mathrm{~L}^{-1}\right)$} & \multicolumn{2}{|c|}{ BAcAm $\left(\mu g \mathrm{~L}^{-1}\right)$} \\
\hline & $\mathrm{SO}_{4}{ }^{--} / \mathrm{Br}^{-}$ & $\mathrm{HOBr}$ & $\mathrm{SO}_{4}{ }^{\circ-} / \mathrm{Br}^{-}$ & $\mathrm{HOBr}$ & $\mathrm{SO}_{4}{ }^{--} / \mathrm{Br}^{-}$ & $\mathrm{HOBr}$ & $\mathrm{SO}_{4}{ }^{--} / \mathrm{Br}^{-}$ & $\mathrm{HOBr}$ & $\mathrm{SO}_{4}{ }^{\circ-} / \mathrm{Br}^{-}$ & $\mathrm{HOBr}$ & $\mathrm{SO}_{4}{ }^{\bullet-} / \mathrm{Br}^{-}$ & $\mathrm{HOBr}$ & $\mathrm{SO}_{4}{ }^{\circ-} / \mathrm{Br}^{-}$ & $\mathrm{HOBr}$ & $\mathrm{SO}_{4}{ }^{\circ-} / \mathrm{Br}^{-}$ & $\mathrm{HOBr}$ \\
\hline \multicolumn{17}{|l|}{ Group I } \\
\hline L-Asparagine & 294.0 & 1574.2 & 126.3 & 233.3 & 1.1 & 1.0 & ND & ND & ND & ND & 2.4 & 112.9 & 117.4 & 1068.6 & 14.0 & ND \\
\hline L-Glutamic acid & 93.0 & 77.3 & 17.0 & 0.16 & 1.8 & ND & ND & ND & 0.8 & 0.090 & 2.9 & 1.83 & 6.1 & 5.0 & 4.1 & ND \\
\hline L-Phenylalanine & 48.9 & 61.5 & 4.1 & 0.16 & 1.9 & ND & ND & ND & 1.0 & ND & 2.7 & 2.19 & 4.5 & 5.0 & 3.8 & ND \\
\hline L-Tryptophan & 165.8 & 153.0 & 2.0 & 0.65 & 1.4 & ND & ND & ND & ND & 4.39 & 2.3 & 1.92 & 4.5 & 11.3 & 3.9 & ND \\
\hline L-Tyrosine & 1406.2 & 1302.6 & 5.9 & 1.6 & 1.5 & ND & ND & 6.1 & 0.2 & 85.6 & 2.4 & 2.5 & 4.8 & 6.9 & 3.4 & ND \\
\hline L-aspartic acid & 609.5 & 393.9 & 198.3 & 0.71 & 18.3 & ND & ND & ND & 15.2 & 36.30 & 29.2 & 5.8 & 6.5 & 6.3 & ND & ND \\
\hline \multicolumn{17}{|l|}{ Group II } \\
\hline Phenol & 1069.0 & 1988.5 & 2.8 & 0.25 & 0.2 & ND & ND & 4.0 & ND & 141.2 & NA & NA & NA & NA & NA & NA \\
\hline Hydroquinone & 163.2 & 314.6 & 19.1 & 1.85 & 1.9 & ND & ND & 5.5 & 9.3 & 32.5 & NA & NA & NA & NA & NA & NA \\
\hline Salicylic acid & 1694.2 & 2054.2 & 28.9 & 0.70 & 1.4 & ND & ND & 3.4 & 17.2 & 51.0 & NA & NA & NA & NA & NA & NA \\
\hline \multicolumn{17}{|l|}{ Group III } \\
\hline Citric acid & 1435.0 & 1185.8 & 434.6 & 198.5 & 85.3 & 9.9 & 1.9 & 4.0 & 1144.3 & 966.3 & NA & NA & NA & NA & NA & NA \\
\hline Oxalic acid & 147.0 & 91.5 & 0.5 & 0.090 & ND & ND & ND & ND & 4.6 & 23.8 & NA & NA & NA & NA & NA & NA \\
\hline Malonic acid & 59.4 & 652.6 & 8.7 & 488.1 & 3.2 & 20.5 & ND & ND & 15.9 & 0.59 & NA & NA & NA & NA & NA & NA \\
\hline Succinic acid & 601.1 & 60.3 & 14.0 & 0.12 & 1.7 & ND & 4.3 & ND & 606.9 & 52.8 & NA & NA & NA & NA & NA & NA \\
\hline Maleic acid & 324.9 & 762.7 & 3.6 & 0.15 & 0.1 & ND & 2.6 & 4.6 & 149.2 & 30.2 & NA & NA & NA & NA & NA & NA \\
\hline Pyruvic acid & 395.0 & 261.4 & 29.7 & 0.69 & 2.5 & 2.9 & ND & ND & 396.4 & 278.9 & NA & NA & NA & NA & NA & NA \\
\hline
\end{tabular}

Note: Incorporation of bromine into model compounds by SR-AOP: PMS = $100 \mu \mathrm{M}$; $\mathrm{CuFe}_{2} \mathrm{O}_{4}$ dose $=50 \mathrm{mg} \mathrm{L}{ }^{-1}$; bromide $=50 \mu \mathrm{M}$; model

compound $=50 \mu \mathrm{M} ; \mathrm{pH}=8.0$ in $10 \mathrm{mM}$ tetraborate buffer; contact time $24 \mathrm{~h}$. Bromination of model compounds: $\mathrm{HOBr} / \mathrm{OBr}{ }^{-}=50 \mu \mathrm{M}$; model

compound $=50 \mu \mathrm{M} ; \mathrm{pH}=8.0$ in $10 \mathrm{mM}$ tetraborate buffer; contact time $24 \mathrm{~h}$. The results are the average values of duplicate tests. ND: not detected;

NA: not applicable. 
(a)

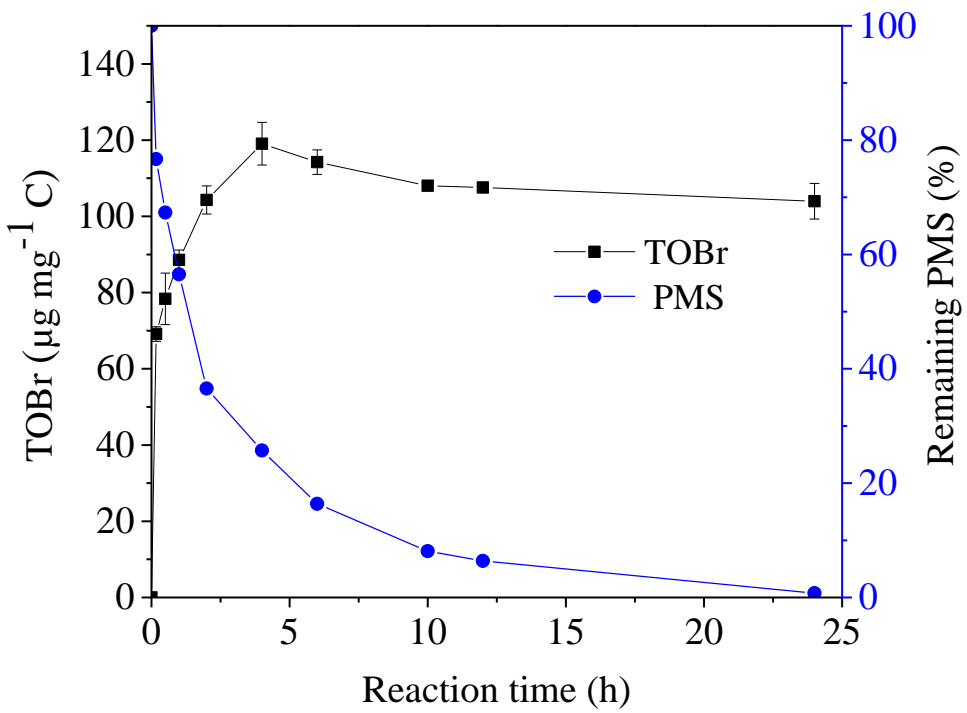

(b)

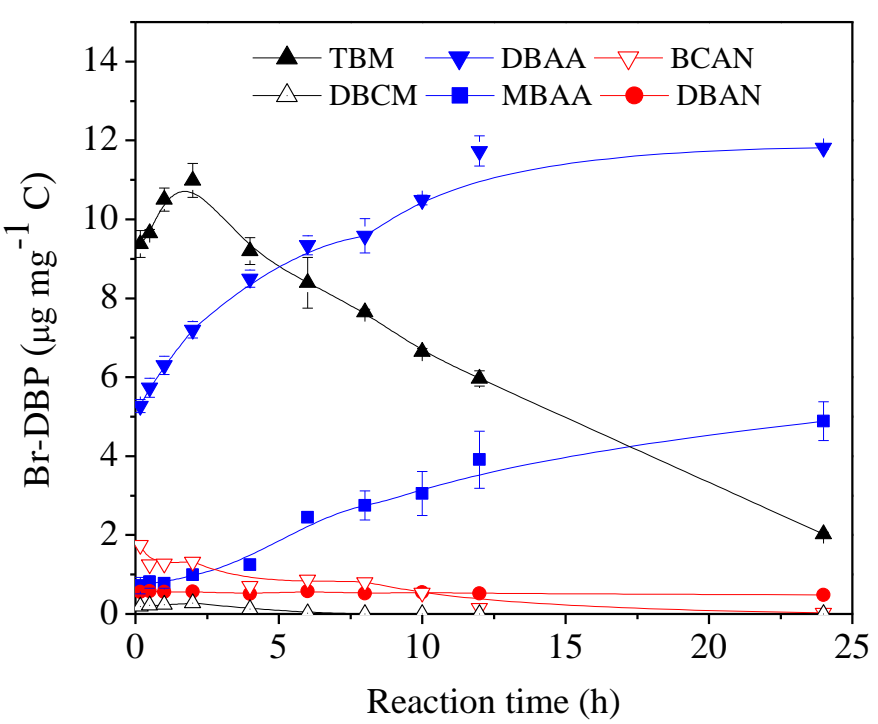

Figure 1. Kinetics of $\mathrm{TOBr}$ and $\mathrm{Br}-\mathrm{DBPs}$ formation from bromide-containing water by SR-AOP:

(a) decomposition of PMS and evolution profile of TOBr; (b) evolution profiles of Br-DBP. Experimental conditions: $5 \mathrm{mg}$ solid SR HPOA per liter MQ (2.25 mg L $\left.{ }^{-1} \mathrm{DOC}\right)$; PMS = $50 \mu \mathrm{M}$; $\mathrm{CuFe}_{2} \mathrm{O}_{4}=50 \mathrm{mg} \mathrm{L}^{-1} ; \mathrm{Br}^{-}=25 \mu \mathrm{M} ; \mathrm{T}=20^{\circ} \mathrm{C} ; \mathrm{pH}=7.5$. 
(a)

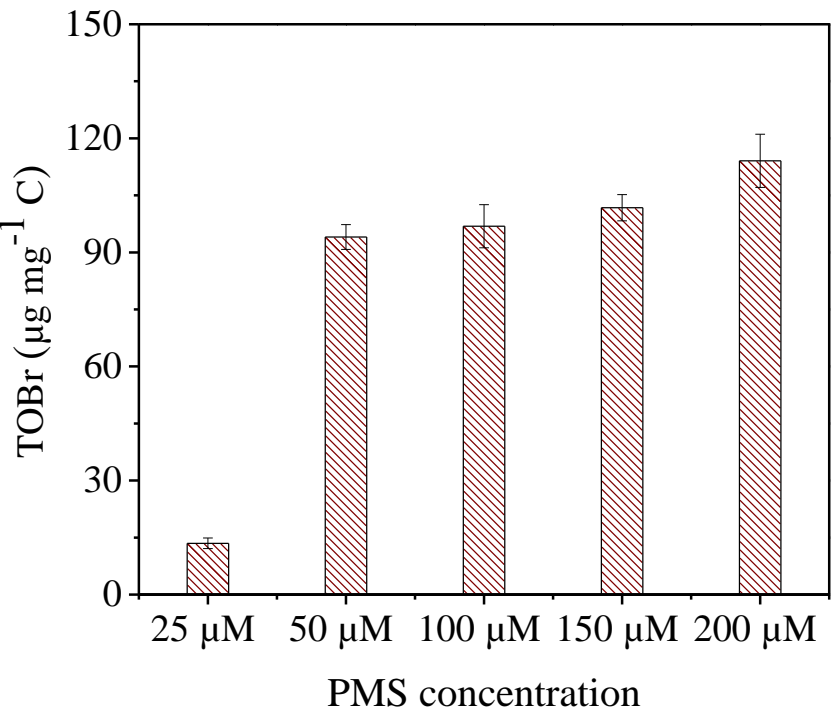

(b)

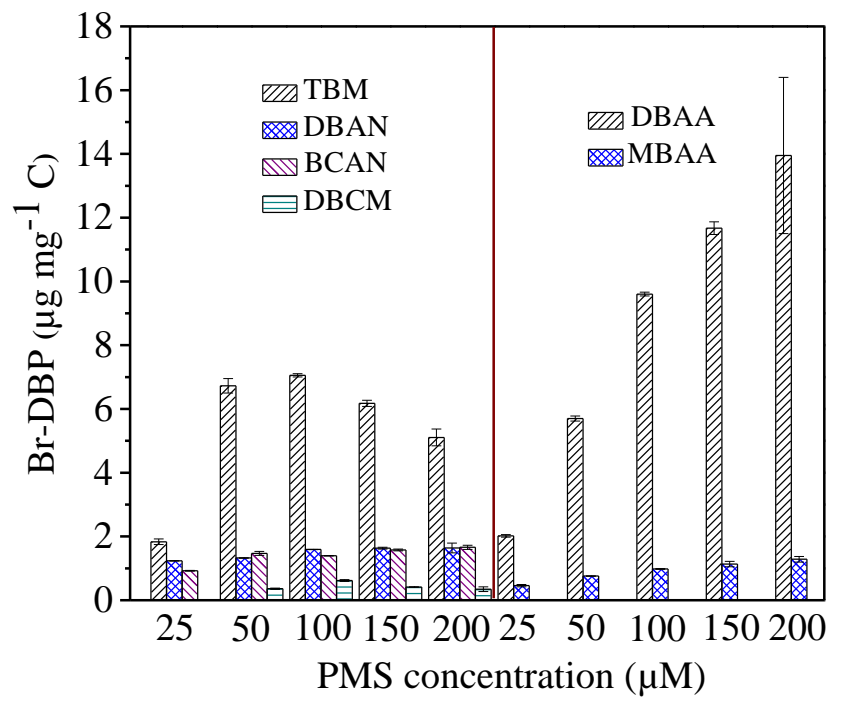

Figure 2. Effect of PMS concentration on the formation and speciation of TOBr and Br-DBPs by SR-AOP: (a) Bromine incorporation into TOBr; (b) THMs, HANs, and HAAs speciation. Experimental conditions: $5 \mathrm{mg}$ solid SR HPOA per liter MQ (2.25 mg L $\mathrm{moC}^{-1}$; $\mathrm{CuFe}_{2} \mathrm{O}_{4}=50$ $\mathrm{mg} \mathrm{L}^{-1} ; \mathrm{Br}^{-}=25 \mu \mathrm{M}$; contact time $=2 \mathrm{~h} ; \mathrm{T}=20^{\circ} \mathrm{C} ; \mathrm{pH}=5.5$. 
(a)

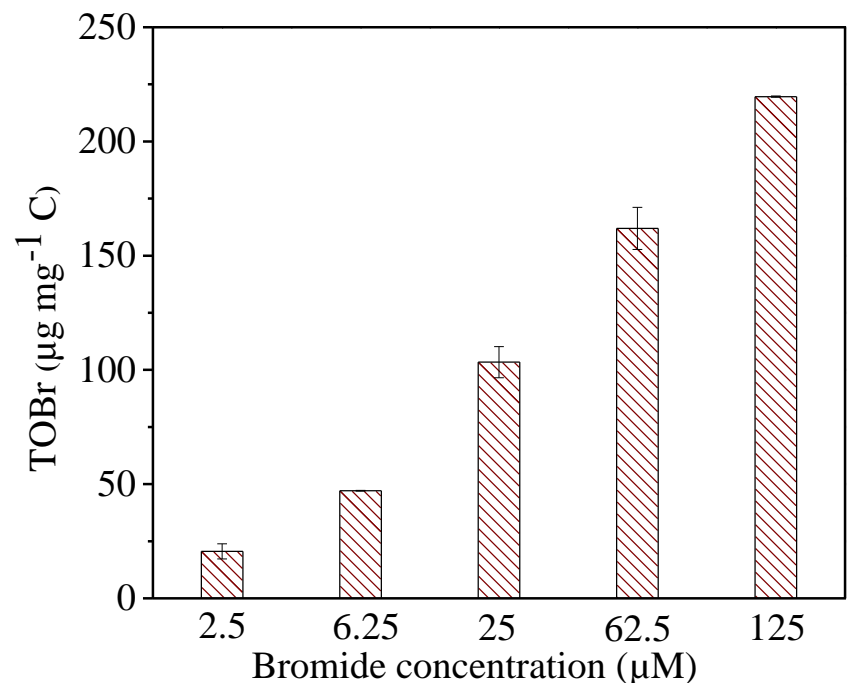

(b)

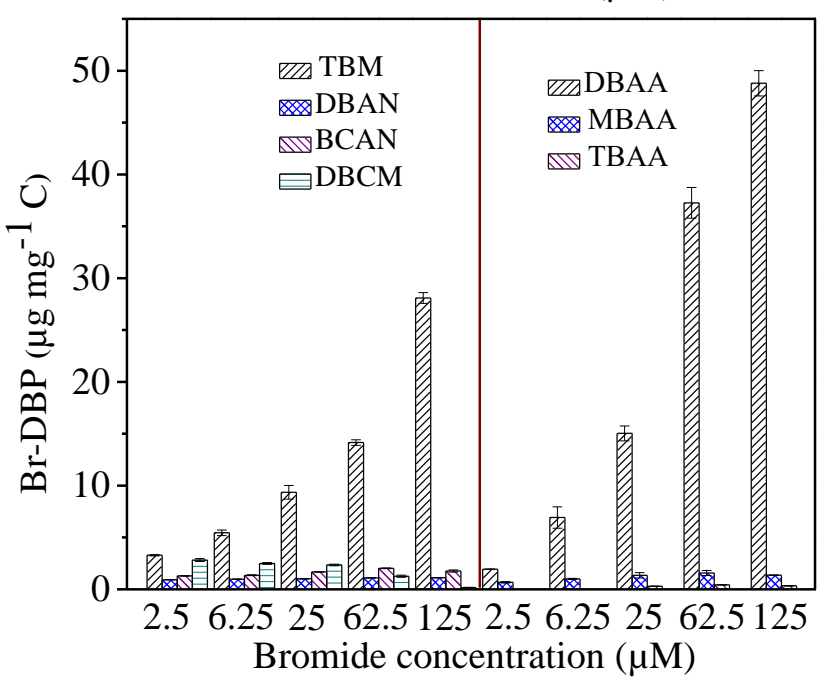

Figure 3. Bromine incorporation into $\mathrm{TOBr}$ and $\mathrm{Br}$-DBPs under various bromide concentrations: (a) Bromine incorporation into TOBr; (b) THMs, HANs, and HAAs speciation. Experimental conditions: $5 \mathrm{mg}$ solid SR HPOA per liter MQ (2.25 mg L-1 DOC); PMS = $100 \mu \mathrm{M} ; \mathrm{CuFe}_{2} \mathrm{O}_{4}=$ $50 \mathrm{mg} \mathrm{L}{ }^{-1} ;$ contact time $=2 \mathrm{~h} ; \mathrm{T}=20^{\circ} \mathrm{C} ; \mathrm{pH}=7.5$ 
(a)

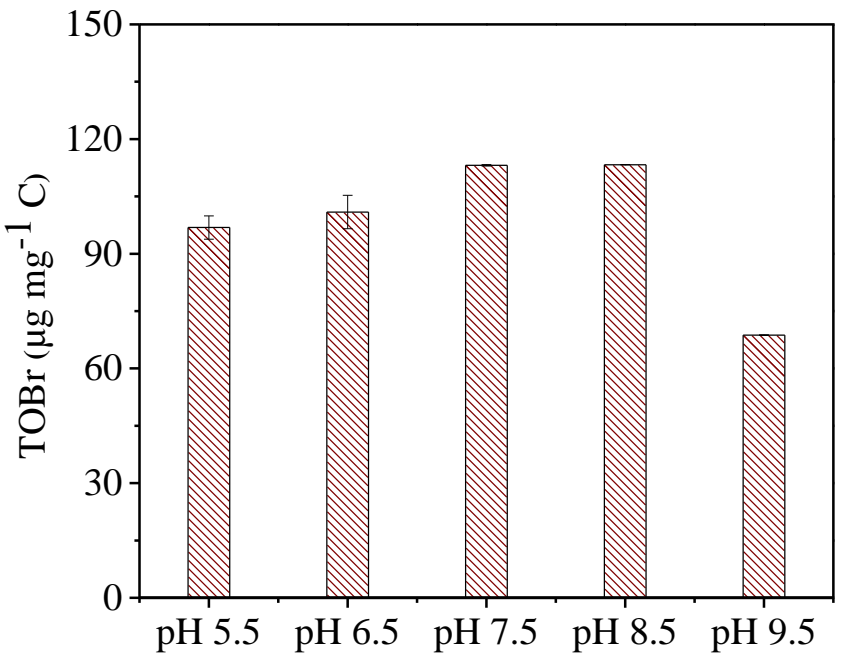

(b)

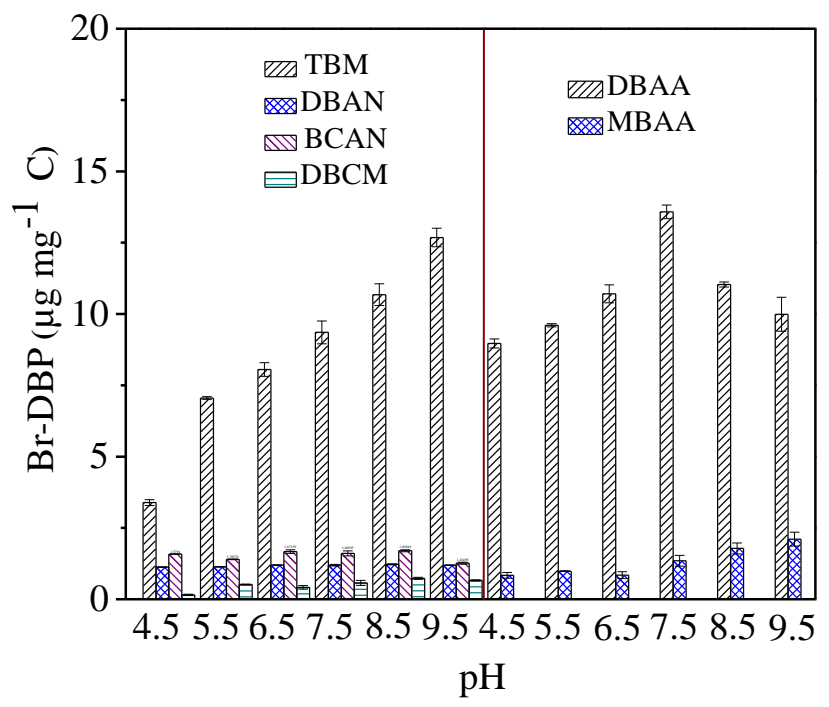

Figure 4. Effect of solution $\mathrm{pH}$ on the formation and speciation of TOBr and Br-DBPs by SRAOP: (a) Bromine incorporation into TOBr; (b) THMs, HANs, and HAAs speciation.

Experimental conditions: $5 \mathrm{mg}$ solid SR HPOA per liter MQ (2.25 mg L $\left.\mathrm{m}^{-1} \mathrm{DOC}\right)$; PMS = 100 $\mu \mathrm{M} ; \mathrm{CuFe}_{2} \mathrm{O}_{4}=50 \mathrm{mg} \mathrm{L}^{-1} ;$ bromide $=25 \mu \mathrm{M}$; contact time $=2 \mathrm{~h} ; \mathrm{T}=20{ }^{\circ} \mathrm{C}$. 
(a)

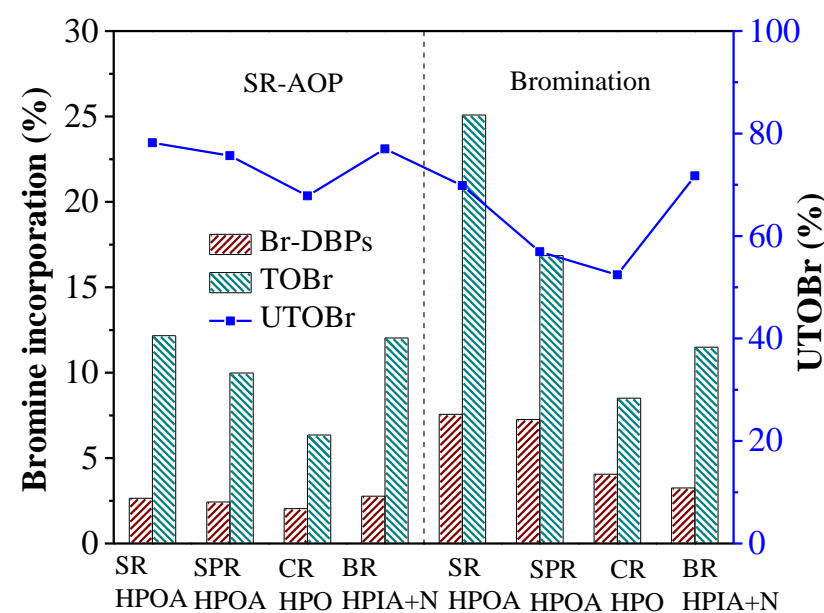

(b)

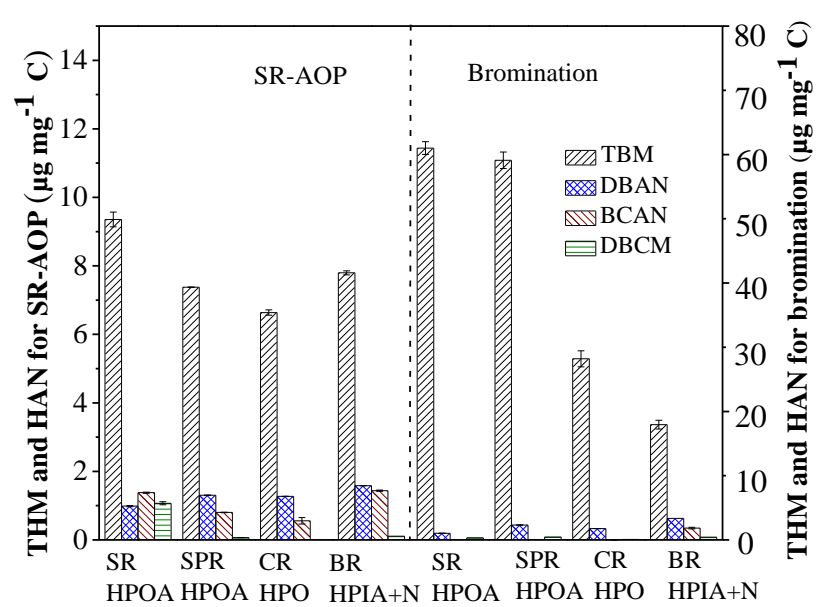

(c)

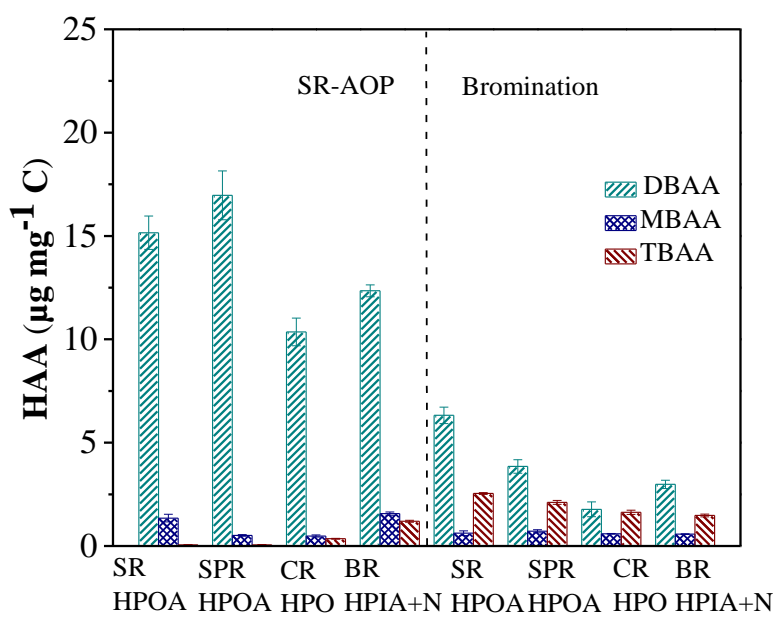

Figure 5. Formation and speciation of TOBr and Br-DBPs from NOM isolates by SR-AOP and bromination: (a) Proportion of unknown compounds in $\mathrm{TOBr}(\mathrm{UTOBr})$ and bromine incorporation into TOBr and Br-DBPs; (b) THMs and HANs speciation; (c) HAAs speciation. Experimental conditions: 5 - $7 \mathrm{mg}$ solid $\mathrm{NOM}$ isolate per liter $\mathrm{MQ} ; \mathrm{pH}=7.5$; contact time $=2 \mathrm{~h} ; \mathrm{T}=20^{\circ} \mathrm{C}$; for $\mathrm{SR}-\mathrm{AOP}, \mathrm{PMS}=100 \mu \mathrm{M}, \mathrm{CuFe}_{2} \mathrm{O}_{4}=50 \mathrm{mg} \mathrm{L}^{-1}$, $\mathrm{Br}^{-}=25 \mu \mathrm{M}$; for bromination, $\mathrm{HOBr} / \mathrm{OBr}^{-}=25 \mu \mathrm{M}$. 